\title{
TRANSNACIONALIZAÇÃO E MERCADORIZAÇÃO DA EDUCAÇÃO SUPERIOR: EXAMINANDO ALGUNS EFEITOS COLATERAIS DO CAPITALISMO ACADÊMICO (SEM RISCOS) NO BRASIL - A EXPANSÃO PRIVADO-MERCANTIL*
}

\author{
TRANSNATIONALIZATION AND COMMODIFICATION OF HIGHER EDUCATION: \\ EXAMINING SOME EFFECTS OF ACADEMIC CAPITALISM (WITHOUT RISK) \\ IN BRAZIL - THE PRIVATE BUSINESS EXPANSION \\ TRANSNACIONALIZACIÓN Y LA MERCANTILIZACIÓN DE LA EDUCACIÓN SUPERIOR: \\ EXAMEN DE ALGUNOS EFECTOS SECUNDARIOS DEL CAPITALISMO ACADÉMICO \\ (SIN RIESGO) EN BRASIL - LA EXPANSIÓN PRIVADA-MERCANTIL
}

Mário Luiz Neves de Azevedo ${ }^{1}$

\begin{abstract}
RESUMO
Este artigo tem por objetivo analisar o processo de mercadorização da educação superior no Brasil, com um foco especial sobre a transnacionalização e a provisão de ensino superior por instituições que visam lucro. Com base em uma abordagem da teoria crítica, como a elaborada por Susan Robertson, Roger Dale, Immanuel Wallerstein, Sheila Slaughter, Larry Leslie, Florestan Fernandes e Pierre Bourdieu, apresenta-se o argumento de que a mercadorização da educação superior foi destravada a partir da promulgação da LDB 9394 (Lei de Diretrizes e Bases da Educação Nacional), em 1996, e catalisada por programas federais como o PROUNI (Programa Universidade para Todos) e FIES (Fundo de Financiamento ao Estudante do Ensino Superior), gerando uma espécie de "capitalismo acadêmico sem riscos" no Brasil.
\end{abstract}

PALAVRAS-CHAVE: Educação superior. Transnacionalização. Mercadorização. PROUNI. FIES.

\begin{abstract}
This article aims to analyze the process of commodification of higher education in Brazil, with a special focus on transnationalization and for-profit providers. Based on an approach of critical theory, as developed by Susan Robertson, Roger Dale, Immanuel Wallerstein, Sheila Slaughter, Larry Leslie and Pierre Bourdieu, presents the argument that the commodification of higher education was unlocked from the enactment of LDB 9394 (Law of Directives and Bases of National Education), in 1996, and catalyzed by federal programs such as PROUNI (University for all Program) and FIES (Higher Education scholarship fund), generating a kind of "academic capitalism without risk" in Brazil.
\end{abstract}

KEYWORDS: Change Higher Education. Transnationalization. Commodification. PROUNI. FIES.

\footnotetext{
* Este artigo é uma versão modificada, com novas informações e discussões, de capítulo de livro que está sendo organizado no quadro da programação do XXIII Seminário Nacional da rede Universitas/Br, que reuniu pesquisadores em torno da temática da expansão privado-mercantil da Educação Superior, na Universidade Federal do Pará (UFPA), em Belém (PA), entre os dias 20 e 23 de maio de 2015.

1 Professor na Universidade Estadual de Maringá. Pesquisador do CNPq e do OBEDUC-CAPES-UERJ. E-mail: mlnazevedo@uem.br

Recebido em: 03/08/2015 - Aceito em: 22/09/2015
}

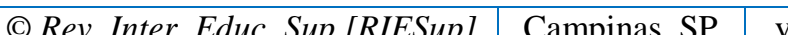




\section{RESUMO}

Este artículo tiene como objetivo analizar el proceso de mercantilización de la educación superior en Brasil, con un enfoque especial en la transnacionalización y la provisión de la educación superior en instituciones con fines de lucro. Con base en el enfoque de la teoría crítica, como el desarrollado por Susan Robertson, Roger Dale, Immanuel Wallerstein, Sheila Masacre, Larry Leslie, Florestan Fernandes y Pierre Bourdieu, presenta el argumento de que la mercantilización de la educación superior se realizó desde el la promulgación de la LDB 9.394 (Ley de Directrices y Bases de la Educación Nacional) en 1996, y catalizada por programas federales como PROUNI (Programa Universidad para Todos) y FIES (Fondo para la Financiación de Estudiantes de Educación Superior), generando una especie de "capitalismo académico sin riesgo" en Brasil.

PALAVRAS CHAVE: Mudança na universidade. Comercialização da ciência. Pesquisas comercializáveis.

\section{INTRODUÇÃO}

Se o analista cuidadoso se confundir ao observar esse redemoinho institucional, poderá clarear as ideias lembrando-se de que no capitalismo histórico os acumuladores não têm objetivos mais altos do que obter mais acumulação. Logo, as forças de trabalho não podem ter objetivos mais altos do que a própria sobrevivência e a redução do seu fardo. Lembrando disso, poderemos compreender em grande parte o sentido da história política do mundo moderno (WALLERSTEIN, 2001, p. 57).

O presente artigo analisa o processo de mercadorização da educação superior no Brasil, com um foco especial sobre o fenômeno da transnacionalização. A mercadorização pode ser interpretada como um modo de liberalização da oferta de ensino que pode ocorrer de diversas maneiras: expansão do ensino superior privado-mercantil (for profit higher education), privatização direta, desresponsabilização do Estado, criação de quase-mercado, estabelecimento de Parcerias-Público-Privado (PPP), estímulo à competição, performatividade, rankings, indicadores etc. (DALE, 1994; CABRITO, 2011; AFONSO, 1999; SGUISSARDI, 2015; OLIVEIRA, 2009; BALL, 2004).

A transnacionalização seria a oferta transfronteiriça de ensino, presencial ou a distância, por intermédio de organizações transnacionais de serviços educacionais com finalidade de lucro. Vale notar, no entanto, que há Instituições de Ensino Superior Privadas com sede no Brasil que são cotadas em bolsa e que têm participação acionária de indivíduos, sociedades, associações e fundos de capitais de origem estrangeira, caracterizando-se, por isso, também como uma modalidade de transnacionalização.

A transnacionalização do ensino superior, em lugar de resolver questões relativas à carência de provisão de um bem público estratégico, pode provocar tensões que são próprias do mundo das mercadorias. Karl Polanyi (2000) alerta que relações baseadas em princípios individualistas e de mercado corroem os laços sociais, desgastam a solidariedade e destroem a coesão e a integração sociais, nutrindo fundamentalismos e instalando carências, rivalidades e paixões negativas. 
Assim, mesmo se tratando da educação, atividade potencialmente promotora da solidariedade, da coesão e da integração (aliás, apesar disso); pelo fato de ser provisionada por entes privados com finalidade de lucro, ainda que por concessão pública e com qualidade certificada, seu tratamento como mercadoria gera o contrário de sua potencialidade, erodindo as relações humanas baseadas na solidariedade, fraternidade, coesão, unidade e integração (POLANYI, 2000). Isto tudo sem desconsiderar que a prática de mercado, tendencialmente, cria oligopólios e, no limite, o "imperialismo cultural" (BOURDIEU; WACQUANT, 2002) ${ }^{2}$ dos países centrais no sistema-mundo que, sob a justificativa de promover uma suposta cultura universal "neutra" (WALLERSTEIN, 2001), na realidade, pode provocar, segundo os centros dos espaços geográficos, a norte-americanização ou a europeização culturais (DALE; ROBERTSON, 2009; AZEVEDO, 2014), com o beneplácito de organizações internacionais, a exemplo de Banco Mundial, Organização para a Cooperação e Desenvolvimento Econômico OCDE e Organização Mundial do Comércio (OMC), think tanks ${ }^{3}$, autoridades regionais, como aquelas vinculadas à União Europeia, ao Tratado Norte-Americano de Livre Comércio (TLCAN, em inglês: North American Free Trade Agreement - NAFTA), à Associação de Nações do Sudeste Asiático (ASEAN, em inglês: Association of Southeast Asian Nations; ANSEA) e ao Mercado Comum do Sul (MERCOSUL), e outras organizações e instituições com vocação internacional. De acordo com Wallerstein,

\begin{abstract}
O universalismo serviu para dirigir as atividades da burguesia de outros Estados e de vários estratos médios mundo afora para canais capazes de maximilizar a integração dos processos de produção e tornar mais suave a operação do sistema intestatal, facilitando assim a chamada acumulação de capital. Para tal, era necessário criar uma estrutura cultural burguesa mundial, passível de ser enxertada nas variações 'nacionais'. Isso foi particularmente importante em termos de ciência e tecnologia, mas também no espaço das ideias políticas e das ciências sociais (2001, p. 72).
\end{abstract}

Portanto, nacionalmente, o campo de poder, o campo da educação e o campo acadêmico (em especial, as instituições de educação superior) são passíveis de aceitarem e receberem, crítica ou acriticamente, a transferência de políticas (DOLOWITZ; MARSH, 2000), a "bricolagem" de políticas (BALL, 2001) e a "agenda globalmente estruturada para a educação" (DALE, 2004), concorrendo para o sucesso do "capitalismo acadêmico"4 (SLAUGHTER; LESLIE, 1997), fenômeno social que, a propósito, torna-se o "meio de cultura" (mercadorizante) ainda mais favorável à transnacionalização da educação superior.

\footnotetext{
${ }^{2}$ Segundo Bourdieu e Wacquant, "a violência simbólica nunca se exerce, de fato, sem uma forma de cumplicidade (extorquida) daqueles que a sofrem e a 'globalização' dos temas da doxa social americana ou de sua transcrição, mais ou menos sublimada, no discurso semi-erudito não seria possível sem a colaboração, consciente ou inconsciente, direta ou indiretamente interessada, não só de todos os 'passadores' e importadores de produtos culturais (...), mas também de todas as instâncias culturais americanas (...)” (2002, p. 24).

${ }^{3}$ Literalmente seriam reservatórios ou tanques de pensamento, mas a expressão think tank pode ser interpretada como sendo instituto, fundação, associação e congêneres que têm a finalidade de produzir propostas, análises e interpretações, cedendo-as ao Governo, Estado e demais interessados.

${ }^{4}$ Em nota de rodapé, Slaughter e Leslie advertem que "Nós não somos os primeiros a usar a expressão capitalismo acadêmico. Edward J. Jackett (1990) a utiliza para sintetizar as importantes mudanças estruturais na ciência acadêmica (...)". No original: "We are not the first to use the term academic capitalism. Edward J. Jackett (1990) uses the term to summarize important structural changes in academic science (...)" (SLAUGHTER; LESLIE, 1997, p. 8).
} 
Por isso, vale a pena conferir a explicação dos pesquisadores norte-americanos a respeito da expressão "capitalismo acadêmico":

(...) a palavra capitalismo conota a propriedade privada dos fatores de produção terra, trabalho e capital - e considerar funcionários de universidades públicas como capitalistas, à primeira vista, parece uma flagrante contradição. No entanto, o capitalismo também é definido como um sistema econômico em que as decisões de alocação são movidas por forças de mercado (SLAUGHTER; LESLIE 1997, p. 9) ${ }^{6}$.

O capitalismo acadêmico, para além dos países da amostra de pesquisa de Slaughter e Leslie (1997), tem avançado globalmente. Na realidade, os princípios de mercado têm produzido variados efeitos em outros campos de educação superior nacionais. No Brasil, por exemplo, sem desconsiderar as influências similares na esfera pública, o capitalismo acadêmico deitou raízes no campo educacional por intermédio da expansão das instituições de ensino superior privadas, as quais possuem quase $3 / 4$ (três quartos) das matrículas totais na graduação, demonstrando a consolidação de um verdadeiro mercado de educação superior no Brasil. Em números mais precisos, segundo o Instituto Nacional de Estudos e Pesquisas Educacionais Anísio Teixeira (INEP) do Ministério da Educação (MEC), 5.373.450 estavam matriculados em 2.090 estabelecimentos privados, em um conjunto de 2.391 instituições de educação superior que totalizavam 7.305.977 estudantes de graduação matriculados em (IES), correspondendo a 73,5\% do universo discente e 87,4\% das IES (INEP, 2014). Segundo Azevedo,

pela proporção de matrículas em instituições privadas, pode-se dimensionar o mercado de educação superior no Brasil. Segundo o INEP, pouco mais de $25 \%$ vagas ( $1 / 4$ do total) são preenchidas em instituições públicas. Esta é uma saliente evidência da privatização da oferta de educação superior no País e da transformação da maioria dos estudantes em consumidores de educação, que pagam diretamente anuidades escolares ou que são financiados por intermédio de bolsas pelo Programa Universidade para Todos (PROUNI) ou pelo Fundo de Financiamento Estudantil (FIES) (2015, p. 1150).

\section{O CAPITAlisMo ACADÊMico, O PRIVAdo MERCANTIL E A TRANSNACIONALIZAÇÃO DA EDUCAÇÃO SUPERIOR NO BRASIL}

(...) o capital ganhou terreno às custas do Estado e o Estado agora está apoiando e garantindo o capital de maneiras que não precisava antes. Então aqueles problemas centrais permanecem: o capital não pode prover as condições de sua própria existência por conta de sua vulnerabilidade intrínseca. Não pode prover condições

\footnotetext{
${ }^{5}$ Para o desenvolvimento da pesquisa sobre o "capitalismo acadêmico", Slaughter e Leslie elegeram as instituições públicas de educação superior de quatro países como amostra para a pesquisa (Estados Unidos da América, Austrália, Canadá e Reino Unido), deixando de fora as instituições privadas de ensino superior, isto porque, segundo os pesquisadores, nestes países o ensino não é gratuito e a oferta privada de educação superior nos EUA corresponde a $20 \%$ da população estudantil e nos outros três países é irrelevante (1997, p. 12).

6 "(...) the word capitalism connotes private ownership of the factors of production - land, labor and capital and considering employees of public research universities to be capitalist at first glance seems a blatant contradiction. However, capitalism also is defined as an economic system in which allocation decisions are driven by market forces" (SLAUGHTER; LESLIE, 1997, p. 9)
}

\begin{tabular}{l|l|l|l|l|l|l}
\hline (C) Rev. Inter. Educ. Sup.[RIESup] & Campinas, SP & v.1 & n.1 & p. 86-102 & jul./set. 2015 & ISSN 2446-9424 \\
\hline
\end{tabular}


de coesão social. E tais condições são uma das coisas que se moveram muito do nível nacional para o nível transnacional. (DALE, 2014, p. 6).

Em estudo apresentado ao CNE (Conselho Nacional de Educação), Sguissardi (2015) afirma que a educação superior no Brasil vive um processo de mercantilização e que este processo "tende a pôr em dúvida a tese da democratização e a afirmar, ao menos como hipótese, a emergência de uma massificação nada ou muito pouco democrática" (2015, p. 4). A Hoper Estudos de Mercado, em consultoria para a Sociedade de Educação Tiradentes, afirma que a presença majoritária do setor privado no ensino superior brasileiro deve-se, "principalmente, à incapacidade do setor público de atender à demanda de estudantes de nível superior" (2009, p. 15). Indo além, tomando por base os dados de 2008, o texto é ainda mais provocativo,

em virtude de um viés ideológico histórico, o setor de ensino superior público no Brasil ainda é fortemente elitizado. Oferece atualmente apenas 330 mil vagas anuais $(12 \%$ do total de vagas), para atender a uma demanda anual de egressos do ensino médio de aproximadamente 2,1 milhões de jovens (concluintes do ensino médio regular mais os concluintes do EJA - Educação de Jovens e Adultos). O setor público deixa de atender à demanda de 1.770 .000 jovens anualmente - os "excluídos" do sistema público. O setor privado consegue, por sua vez, absorver parte desses "excluídos", algo em torno de 825 mil ingressantes com idade inferior a 24 anos, que podem pagar a mensalidade, ficando os restantes 945 mil estudantes/ano sem nenhuma oportunidade de ingressar num curso superior, engrossando a massa dos mais de 7 milhões de "excluídos" do sistema. Tal realidade faz com que o Brasil ostente uma das piores posições no ranking divulgado pela OCDE no que se refere às taxas de escolarização superior (HOPER, 2009, p. 15).

Entretanto, deve-se atentar, o "viés ideológico" mais proeminente na história do País é do favorecimento do privado, seja pelo "cercamento" e pela ocupação dos espaços públicos pelas elites e demais entes privados, seja pelo incentivo à expansão mercantil, inclusive, na provisão de bens públicos por concessões à organizações privadas, tais como os trabalhos de educação, saúde, saneamento, água, energia, comunicação, tabelionato e "fé pública" (cartórios).

Na História recente da educação, a expansão privado-mercantil foi desembreada das engrenagens da regulação mais estrita após a promulgação da Lei de Diretrizes e Bases da Educação Nacional (LDB), Lei 9.394, de 20 dezembro de 1996, e com o Decreto n. 2.306, de 17 de agosto de 1997, e o Decreto n. 2.207, de 15 de abril de 1997, consagrando como legais as atividades de ensino executadas por empresas com finalidade de lucro. Sguissardi, baseando-se em dados do INEP, notou que

em 1999, segundo o Censo da ES do Inep, 48\% do total das 1.097 IES do país ou $58 \%$ do total de 905 IES privadas já haviam modificado seus estatutos e se tornado instituições privadas particulares, com finalidade lucrativa ou sociedades mercantis. Em 2010 já eram 77,8\% do total das IES do país e, em 2012, provavelmente seu percentual ultrapasse os $80 \%$ (2015, p. 39).

\footnotetext{
${ }^{7}$ Reflexões sobre o conceito de "cercamento", tendo por referência Polanyi (2013), podem ser encontradas no capítulo "A economia baseada no "cercamento" do conhecimento: globalização, educação e mercadorias fictícias" (Azevedo, 2013).
} 
Portanto, em grande medida, a expansão da educação superior no Brasil aconteceu em ambiente de mercado dominado por empresas de serviços educacionais com finalidade de lucro e, para complexificar ainda mais o panorama, em momento em que a Organização Mundial do Comércio (OMC) $)^{8}$, criada 1995, passa a jogar papel importante na liberalização comercial, reforçando teses privatizantes da educação do Banco Mundial (1994), e em que empresas transnacionais e fundos de investimento lançam-se no mercado de educação superior no Brasil. Em instigante artigo intitulado "A transformação da educação em mercadoria no Brasil", Oliveira afirma que "a primeira manifestação do que hoje se observa foi o estabelecimento, em 2001, de parceria entre o Grupo Pitágoras, de Minas Gerais, e a Apollo internacional" (2009, p. 742). Oliveira chama a atenção para o fato de que esta associação empresarial foi dissolvida em 2006, após a aquisição da totalidade das cotas do Grupo Apollo pelo Grupo Pitágoras (2009, p. 742). Porém, não invalida conferir a declaração ao público dos sócios ao anunciarem o lançamento desta sociedade transnacional de ensino superior:

\begin{abstract}
A Faculdade Pitágoras surgiu da vocação de duas instituições para implementar uma educação superior de qualidade. De um lado, o Grupo Pitágoras, a terceira maior rede privada de ensino do país, com seus mais de 150.000 alunos e uma experiência que vem acumulando êxitos desde 1966. Do outro, a Apollo International, que adaptou, especialmente para a Faculdade Pitágoras, a metodologia da inovadora Universidade de Phoenix, EUA, mantida pelo Grupo Apollo - fundado em 1976 e hoje com 150.000 alunos. Essa parceria de sucesso garante formação profissional com padrão internacional, voltada para um mundo competitivo, globalizado e mutante (apud OLIVEIRA, 2009, p. 742).
\end{abstract}

Ironicamente, a "inovação" mais perceptível da Apollo International não poderia ser chamada exatamente de "inovação", conforme reivindica a nota ao público do Grupo Pitágoras, mas, contraditoriamente, encontra registro na História Econômica do Brasil sob a expressão "capitalismo sem risco da burguesia brasileira" (Fernandes, 1972). Em tempos de capitalismo acadêmico (SLAUGHTER; LESLIE, 1997), este mimetismo, como uma "evolução convergente" aplicada aos negócios educacionais, poderia ser denominado de "capitalismo acadêmico sem riscos". Isto pois, conforme evidenciam os dados, em ambos os hemisférios, tanto a Universidade de Phoenix nos EUA como a Faculdade Pitágoras no Brasil são dependentes de subsídios e financiamentos públicos e o suposto sucesso de ambas não se deriva propriamente da livre escolha de estudantes em um mercado de oferta e procura de ensino superior ${ }^{9}$. De acordo com Douglass,

\footnotetext{
${ }^{8}$ O Acordo Geral sobre Comércio de Serviços (AGCS), resultado da Rodada Uruguai (1986-1994), entra em vigor para os signatários em 1995. Sguissardi ressalta que "embora oficialmente o Brasil se tenha posicionado, nos fóruns do AGCS, da OMC, contrário à liberalização comercial dos 'serviços educacionais', na prática não existiria nenhum impedimento legal que tolha sua comercialização e mercantilização, haja vista a liberação constitucional e legal da educação à iniciativa privada" (2015, p. 107).

${ }^{9}$ As empresas de ensino superior que visam lucro chamam a atenção também pela propaganda, inclusive por inserções em filmes. Billy (Vince Vaughn) e Nick (Owen Wilson), na comédia Os Estagiários (no original, The Internship), são dois quarentões que, depois de verem fechar a empresa em que trabalhavam no ramo de comércio de relógios, resolvem tentar recomeçar a vida no mundo do trabalho como estagiários. Para isso, matriculam-se na Universidade de Phoenix e, em seguida, submetem-se por videoconferência a postos de estagiários na empresa Google Inc. Os dois "estudantes" farão parte de uma equipe composta por aqueles que
} 
o setor de empresas privadas de ensino que visam lucro (For Profit) é altamente dependente de financiamento do contribuinte. Apesar do aumento da demanda por ensino superior, o corrente crescimento deste setor (For Profit) não é fruto do capitalismo de livre mercado. Ele é fortemente subsidiado, junto com a maioria das grandes e pequenas empresas que dependem fortemente de estudantes que recebem ajuda financeira federal e dos Estados [Unidades Federativas]. Por exemplo, o Grupo Apollo, proprietário da Universidade de Phoenix, deriva mais de 80 por cento de todas as suas receitas de estudantes financiados, via empréstimos ou bolsas, pelo governo federal $(2012, \text { p. } 6)^{10}$.

Por sinal, o setor privado de educação no Brasil, de acordo com a Hoper Group, consultoria para área de educação, faturou, em 2013, R \$75,74 bilhões, sendo R \$43,7 bilhões na educação básica e $\mathrm{R} \$ 32,04$ na educação superior, nas modalidades presencial e a distância.

\section{Faturamento Estimado 2014 (Bilhões de reais) Segmentos dos Mercado Educacional Brasileiro}

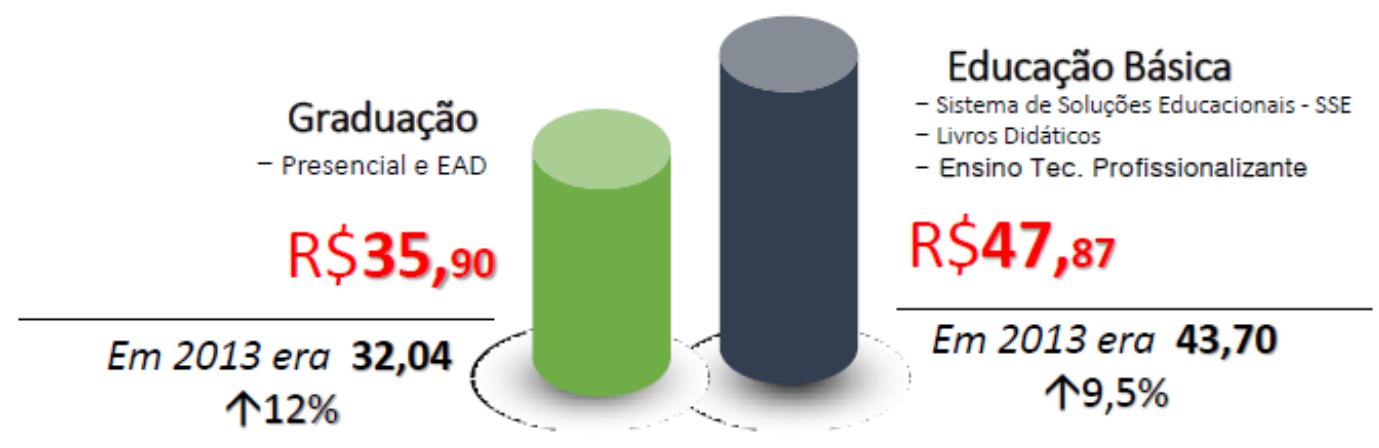

Fonte: HOPER, 2014.

Estes números demonstram a dimensão do atendimento da demanda por educação superior pela iniciativa privada no Brasil. A liberação do campo da educação superior à atuação privado-mercantil, como já mencionado, foi destravada a partir da promulgação da LDB $\mathrm{n}^{\circ}$. 9.394/1996 e potencializada pelo financiamento às IES particulares por agentes privados e públicos (inclusive pelo BNDES), pela atuação de fundos nacionais e estrangeiros e por programas federais de financiamento direto a estudantes de graduação como o FIES (Fundo de Financiamento Estudantil) $^{11}$ e o PROUNI (Programa Universidade para Todos) ${ }^{12}$.

\footnotetext{
não foram escolhidos para as equipes principais. Assim, à maneira de comédias moralistas de Hollywood, os candidatos sobrantes formam um novo time. O sucesso, ao final, não sem muitas turbulências e conflitos, acaba chegando para a equipe em que atuam os dois maduros estudantes da Universidade de Phoenix. Afinal, o otimismo é a tônica da comédia, conforme afirmou um dos personagens: "we are graduates of the online University of Phoenix. That's like the online equivalent of Harvard!" (THE INTERNSHIP, 2013).

${ }^{10 " T h e ~ F P ~ s e c t o r ~ i s ~ h i g h l y ~ r e l i a n t ~ o n ~ t a x p a y e r ~ f u n d i n g . ~ A l t h o u g h ~ t h e ~ p r o d u c t ~ o f ~ r i s i n g ~ d e m a n d ~ f o r ~ h i g h e r ~}$ education, the current FP sector is not the result of free-market capitalism. It is heavily subsidized, with most major and minor enterprises relying heavily on students who receive federal and state financial aid. For example, the Apollo Group, owner of the University of Phoenix, derives over 80 percent of all its revenues from their students' federally funded grants and loans" (DOUGLASS, 2012, p. 6).

${ }^{11}$ O FIES, criado pela Lei no 10.260 , de 12 de julho de 2001, como um Fundo de Financiamento ao Estudante do Ensino Superior.
} 
Sécca e Leal (2009), em análise acerca do ensino superior privado no Brasil, publicada no BNDES Setorial, apresentam cinco hipóteses que, para eles, seriam condicionantes do aumento da demanda por ensino superior no País:

a) Aumento da população jovem adulta (na faixa de 18 a 30 anos, desde 1990);

b) Exigências do mercado de trabalho (o aumento desemprego nos anos 1990 e a maior exposição do Brasil no mercado global exigiram trabalhadores com qualificação superior);

c) Aumento do número de concluintes no ensino médio (o número de concluintes desse nível faz aumentar a demanda de ensino superior);

d) Maior disponibilidade de financiamento estudantil e bolsas de estudo (principalmente pelo FIES e PROUNI);

e) Desregulamentação (com a vigência da LDB 9394/1996) $)^{13}$.

Sem anular nenhuma das cinco hipóteses anteriormente elencadas, ao contrário, reforçado por elas, pode-se argumentar que o setor privado-mercantil cresce na escassez de provisionamento de lugares públicos para aquela maioria que, contraditoriamente, mais precisa de educação pública e gratuita, porém que tem sido atendida por programas federais inspirados em PPP (Parcerias Público-Privadas) ${ }^{14}$.

A propósito, a gestão e a governança da educação por meio de parcerias públicoprivadas (PPP), em tempos de globalização e neoliberalismo ${ }^{15}$, têm sido motivo de variados

\footnotetext{
${ }^{12}$ O PROUNI, instituído pela Lei n ${ }^{\text {o }} 11.096$, de 13 de janeiro de 2005, como um programa do Governo Federal, em que as organizações privadas de ensino superior oferecem bolsas de estudo integrais ou parciais a estudantes de baixa renda e, em contrapartida, são isentas do recolhimento de quatro impostos e contribuições federais (IRPJ - Imposto de Renda das Pessoas Jurídicas, CSLL - Contribuição Social sobre o Lucro Líquido, PIS Programa de Integração Social, Cofins - Contribuição Social para Financiamento da Seguridade Social) (BRASIL, 2005). Se considerados somente os anos 2011, 2012 e 2013, a renúncia fiscal alcançou mais $\mathrm{R} \$ 1,72$ bilhão, em termos nominais (LIRA, 28 ago 2014).

13،No contexto da década de 1990, caracterizado por políticas de privatizações e desregulamentação, um dos fatores relacionados ao crescimento das IES privadas foi a promulgação da nova LDB, de 1996, que flexibilizou o mercado de educação superior. A LDB criou os centros universitários e os cursos sequenciais, permitiu substituir o vestibular por outros processos seletivos, flexibilizou os currículos e criou os cursos de tecnologia, entre outras inovações" (SECCA; LEAL, p. 114) .

${ }^{14}$ Carvalho (2006) percebe que o PROUNI é uma política que atende, ao mesmo tempo, a demanda reprimida e os interesses das empresas privadas de ensino superior que estão com vagas ociosas. Para incentivar a ocupação das vagas e a participação no PROUNI também se recorreu a propagandas e a convites de representantes e autoridades: "Algumas figuras públicas, tais como cantores e sindicalistas, cuja imagem está associada ao 'homem do povo', realizaram propagandas em jornais, revistas e em canais televisivos em prol da importância e do papel de democratização do PROUNI. Vale ressaltar que a Central Única dos Trabalhadores (CUT), um dos principais aliados do atual governo, por meio de seu presidente, mostrou-se simpatizante ao programa em manifestação nos meios de comunicação, alegando ter, afinal, chegado a hora do trabalhador ter acesso ao ensino superior (Marinho, 2005). A legitimidade social do programa encontra ressonância na pressão das associações representativas dos interesses do segmento particular, justificada pelo alto grau de vagas ociosas. $\mathrm{O}$ PROUNI surge como excelente oportunidade de fuga para frente para as instituições ameaçadas pelo peso das vagas excessivas" (CARVALHO, 2006, p. 986).

15 De acordo com Robertson e Verger, "como parte do projeto neoliberal, lançou-se, na década de 1980, um conjunto de ideias-chave com destaque para: a fragmentação das políticas estatais protecionistas, de modo a facilitar a livre movimentação do comércio, das finanças e do trabalho através das fronteiras nacionais
} 
debates. Robertson e Verger notam que, por um lado, alguns analistas interpretam as PPPs no campo da educação como uma novidade mais palatável da agenda de privatização e, por outro lado, as parcerias público-privadas na educação (PPPE) são vistas como inovação no financiamento da educação em que se extrai o melhor do público e do privado para incidir na resolução de problemas sistêmicos dos sistemas de ensino (ROBERTSON; VERGER, 2012).

Entre aqueles que se alinham de maneira favorável às PPPs está o presidente do BNDES (Banco Nacional de Desenvolvimento Econômico e Social), Luciano Coutinho. Em seu discurso no Fórum Econômico Mundial, em Davos, em 2013, compilado pelo jornalista Sérgio Leo, do periódico Valor Econômico, Coutinho afirma que "é preciso garantir a confiabilidade, senso de justiça, legitimidade e previsibilidade na relação com o setor privado (...). A parceria com o setor privado é a única maneira de promovemos, juntos, um círculo virtuoso (...)" (25 Jan 2013).

A demanda de educação superior por cidadãos carentes no País pode ser dimensionada tomando por base alguns dados do FIES e do PROUNI, que, como sabido, são programas dirigidos atender as populações jovens das classes dominadas. Assim, no período de 2005 a 2013, atendeu 1.273.665 estudantes, sendo 873.648 bolsas integrais (69\% do total) e 400.017 bolsas parciais (31\%). Os processos seletivos de 2014 ofereceram 306.726 bolsas, destas 205.237 são integrais (66,9\%) (LORENZONI, 26 dez 2014). Já o FIES, de 2010 a 2014, consignou 1.722.960 contratos de financiamento estudantil (ANUP, 2015), tendo repassado 13,4 bilhões de Reais, somente em 2014, para as instituições privadas de ensino superior no Brasil (Toledo; Saldaña; Burgarelli, 15 Fev 2015) ${ }^{16}$.

(conhecida como desregulação); a implementação de políticas de concorrência entre os setores público e privado destinadas à criação de eficiência; a privatização de uma série de antigas atividades estatais e seu redimensionamento (envolvendo um processo dual de descentralização e recentralização)" (2012, p. 1.134).

16“Para incentivar a adesão ao programa, as universidades usaram várias estratégias: distribuição de tablets, feirões para explicar o financiamento e até prêmios para quem indicar um amigo. As novas regras, porém, estimulam até quem não precisa entrar no programa, uma vez que os juros abaixo da inflação fazem com que o montante a ser pago no futuro seja menor do que o custo da mensalidade atualmente" (...) "muitas faculdades passaram a incentivar alunos já matriculados a não pagar a própria mensalidade, mas a entrar no Fies que, por sua vez, repassa os valores diretamente para as instituições, sem atraso ou inadimplência. Enquanto as empresas têm dinheiro garantido, a dívida fica com o aluno e o risco, com o governo (TOLEDO; SALDAÑA; BURGARELLI, 15 Fev 2015). Além disso, "De acordo com Carlos Monteiro, da CM Consultoria, "como a maioria das instituições acabou transferindo para o Fies aquele aluno que ela dava desconto, que era bolsista, isso gerou o crescimento do ticket médio por aluno quando ela passou a receber do governo" (TOLEDO; OSCAR; SALDAÑA; BURGARELLI, 15 Fev 2015) 


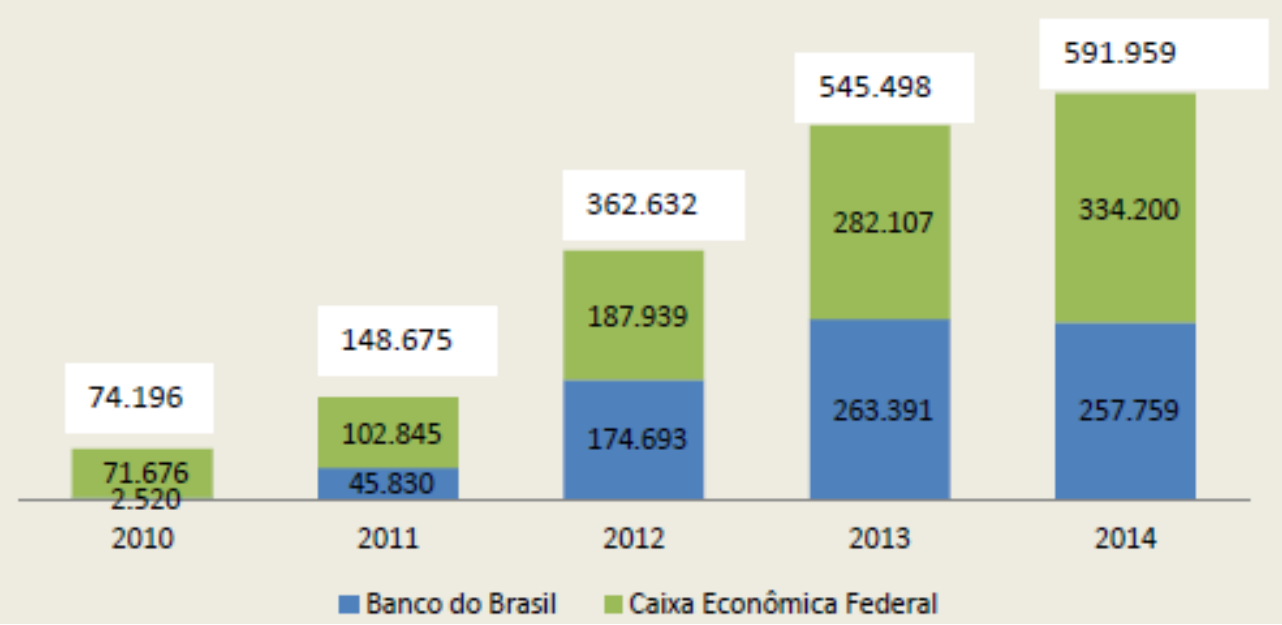

Fonte: ANUP, 2015

A consultoria HOPER, em documento de análise setorial do ensino superior privado de 2009, percebe o promissor "nicho de mercado" e a demanda crescente por este nível de ensino:

Poucos setores da economia brasileira passaram por um movimento de crescimento comparado ao do Ensino Superior Privado. As Instituições de Ensino Superior (IES) Privadas, no Brasil, foram responsáveis por uma expansão de $394 \%$ da oferta de vagas no período 1997-2007 (média de 17,30\% a.a). Um crescimento quase sem precedentes, apenas comparável ao crescimento da oferta de serviços de telecomunicações, após a privatização, e ao crescimento dos serviços financeiros nas décadas de 1980 e 1990 (2009, p. 17).

Desta forma, por intermédio de programas de financiamento direto ao estudante (PROUNI e FIES) e financiamento às empresas de ensino superior, o tesouro público federal tem dado suporte para o desenvolvimento do que poderia ser chamado, no Brasil, de "capitalismo acadêmico sem riscos"17; pois grupos privados (nacionais e estrangeiros) ${ }^{18}$, a exemplo de Laureate International Universities/Universidade Anhembi Morumbi ${ }^{19}$,

\footnotetext{
17،Segundo o professor Celso Napolitano, presidente da Federação dos Professores do Estado de São Paulo (Fepesp), a relação das instituições com o Fies é de 'capitalismo sem risco'. 'Elas não precisam competir por preço, não têm dificuldade de reajustar valores, não têm crise nem problema com aluno" (TOLEDO; SALDAÑA; BURGARELLI, 15 Fev 2015). Ainda, para Toledo, "desde que o governo federal começou a mudar as regras de acesso ao Fundo de Financiamento Estudantil (Fies), em 2010, ser dono de muitas faculdades passou a ser o que há de mais próximo ao capitalismo sem risco no Brasil. O aluno assume um financiamento no Fies, e a faculdade tem a garantia de que receberá integralmente e na data certa o valor da sua mensalidade" (TOLEDO, 16 fev 2014).

${ }^{18}$ De acordo com Mancebo e Vale, "a entrada no Prouni e outras 'ajudas' estatais, acompanhadas de uma eficiente gestão, garantiram à Estácio Participações uma receita bruta, em 2007, de R \$1,3 bilhões e uma receita líquida de R\$ 860 milhões (ESTÁCIO PARTICIPAÇÕES S.A., 2007a, p. 70). Em maio de 2008, a Estácio Participações S.A. celebra a venda de $20 \%$ de seu capital social para a Moena Participações S.A., uma empresa aberta, diretamente controlada pela Garantia Participações (GP), braço de investimento do Banco Garantia" (2013, p. 93).

${ }^{19}$ De acordo com o portal brasileiro na internet do grupo Laureate, a Rede Laureate é composta por mais de 80 instituições, está presente em 29 países e tem mais de 900 mil estudantes matriculados. A partir de documento digital de divulgação, declara-se: "a Anhembi Morumbi convida você a conhecer a Rede Laureate, um dos maiores grupos internacionais de universidades do mundo, com mais de 80 instituições de ensino, em 29 países.
} 
Kroton/Anhanguera Educacional Participações S.A. ${ }^{20}$, Estácio Participações S.A. ${ }^{21}$ e UNIP (Universidade Paulista), têm sido beneficiários colaterais do FIES que ao provisionar recursos na forma de empréstimos aos estudantes, essencialmente, transforma cidadãos em consumidores (endividados) e transfere rendas públicas para a iniciativa privada. Tomando somente esses dois programas como amostra (PROUNI e FIES), pode-se perceber que há um vigoroso processo de mercadorização, privatização e financeirização no campo da educação superior no Brasil. Para ilustrar o que significam estes programas federais nos demonstrativos contábeis dos grupos educacionais privados, listados ou não em bolsas de valores no País ou no exterior, entre 2011 e 2014, cerca de R \$ 24 bilhões foram destinadas a estas empresas a título específico de financiamento de anuidades escolares (TOLEDO; SALDAÑA; BURGARELLI, 15 Fev 2015), sendo que

Kroton Anhanguera (...) foi a empresa que mais recebeu pagamentos do governo federal em 2014. Doze mantenedoras do grupo receberam juntas mais de $\mathrm{R} \$ 2$ bilhões - o dobro do que a Embraer, que fabrica aviões militares, e a Odebrecht, responsável por dezenas de obras pelo País. Outros grupos também figuram entre os líderes de desembolsos do Tesouro em 2014, como a Estácio (R \$ 683 milhões) e a Unip (R \$ 390 milhões). O total a mais gasto com o Fies de 2011 a 2014 em relação ao que se gastava antes das mudanças chega a $\mathrm{R} \$ 24$ bilhões (TOLEDO; SALDAÑA; BURGARELLI, 15 Fev 2015).

Nos EUA, país em que menos de $20 \%$ das IES tem finalidade de lucro (Slaughter; Leslie, 1997), houve um incremento de 235\% neste tipo de instituições, entre 2000 e 2010, aumentando sua participação do mercado (market share), de $3 \%$ para 9,1\%. Por isso, não sem

Essa rede reúne câmpus físicos e on-line que oferecem programas de graduação e pós-graduação aos seus mais de 900 mil estudantes ao redor do mundo. São cursos nas áreas de Engenharia, Educação, Comunicação, Negócios, Saúde, Direito, Arquitetura, Hospitalidade, Artes e Tecnologia da Informação, entre outros (ANHEMBI MORUMBI, 12 Fev 2015, <http://portal.anhembi.br/institucional/rede-internacional-laureate/>).

${ }^{20}$ A Kroton Educacional, de acordo com informações aos investidores, ressalta que "Após a fusão com a Anhanguera, a Kroton passou a contar com 130 unidades de Ensino Superior, presentes em 18 estados e 83 cidades brasileiras, além de 726 Polos de Graduação EAD credenciados pelo MEC localizados em todos os estados brasileiros e também no Distrito Federal. A Companhia ainda conta, na Educação Básica, com mais de 870 escolas associadas em todo o território nacional. Por fim, a fusão com a Anhanguera adicionou ao portfolio mais de 400 polos de cursos livres e preparatórios" (...). Informa também que essa trajetória de forte expansão é inaugurada "no início dos anos 2000 e com a mudança do marco regulatório do setor de educação, surge a primeira Faculdade Pitágoras, com novo sistema de ensino e uma metodologia exclusiva criada em parceria com uma das maiores companhias de educação do mundo - a Apollo International, com sede no Estado do Arizona, nos Estados Unidos da América. Tal parceria durou até 2005 quando a Apollo International decidiu vender sua participação aos fundadores.O ano de 2007 ficou marcado pela abertura de capital do Pitágoras na BM\&FBovespa, com o nome Kroton Educacional (KROT11), possibilitando a consolidação de uma fase de grande expansão e desenvolvimento da Companhia.Já em 2009, a Kroton recebeu um novo aporte financeiro de um dos maiores fundos de private equity do mundo, a Advent International, que a partir de então compartilharia o controle da Companhia com os sócios fundadores" (KROTON, Extraído de <http://www.kroton.com.br/>, Acesso em 12 Fev 2015).

${ }^{21}$ No sítio digital dedicado à relação com os investidores, é declara-se: "somos uma das maiores organizações privadas no setor de ensino superior no Brasil em números de alunos matriculados, de acordo com dados da Consultoria Hoper referentes ao ano de 2011. Em 30 de setembro de 2014, contávamos com 468,9 mil alunos matriculados nas modalidades presencial e à distância, em cursos de graduação e pós-graduação. Nossa rede é formada por uma universidade, seis centros universitários, 36 faculdades e 163 polos de ensino à distância credenciados pelo MEC, com uma capilaridade nacional representada por 84 campi, nos principais centros urbanos de 20 estados brasileiros, estrategicamente localizadas nas proximidades das residências e/ou dos locais de trabalho de nosso público alvo de trabalhadores de classes média e média-baixa” (ESTÁCIO, 22 Fev 2015).

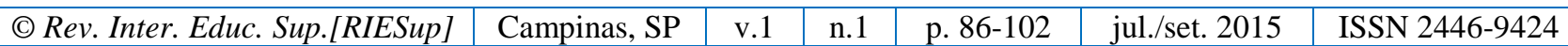


razão, Douglass (2012) denominou este fenômeno mercadorizante no campo da educação superior norte-americano de brazilian effect. Deste modo, pode-se questionar, houve uma transferência inversa de políticas, do Brasil para os EUA? Na contramão da usual convergência de políticas do Brasil em direção aos EUA? Douglass assim explica o "efeito brasileiro" no campo de educação superior norte-americano:

a experiência atual norte-americana é uma versão do que eu chamo de "efeito brasileiro": quando a educação superior pública não pode manter o ritmo exigido pela crescente demanda pública para acesso e programas, governos muitas vezes permitem que empresas que visam lucro (for profit) apressam-se e ajudam a preencher a suprir a demanda, tornando-se muito maior e, por vezes, o provedor dominante. Este é o padrão em muitas economias em desenvolvimento, como o Brasil, em que cerca de 50 por cento dos estudantes estão matriculados em instituições privadas com fins lucrativos, e a Coréia, Polônia e em muitas outras partes do mundo ${ }^{22}$ (DOUGLASS, 2012, p. 2).

Os movimentos de transnacionalização que envolvem a educação superior são próprios do metabolismo do capital, pois faz parte de sua essência o constante processo de busca pela expansão e acumulação, seja por intermédio dos fundos financeiros (private equity), que adquirem partes, cotas ou ações de empresas de ensino superior que visam lucro, ou por grupos provedores de ensino superior que atravessam fronteiras para atuar com permissão e por concessão dos Estados nacionais.

\title{
CONSIDERAÇÕES FINAIS
}

\begin{abstract}
A ideia de que a educação é um direito social e um bem público se contrapõe à concepção de educação como mercadoria que se pode adquirir privadamente, como qualquer item de negócio (...). Nada disso é inócuo (...). A educação é um 'bem comum, público' ou, ao contrário, um ‘bem ou serviço de consumo, privado'? Esta é a grande questão de fundo para as reformas educacionais que hoje se discutem ou se empreendem (DIAS SOBRINHO, 2005, p. 136-137).
\end{abstract}

Para além da transnacionalização por intermédio de fundos financeiros (Private Equity) e de empresas de ensino privadas fornecedoras de ensino que visam lucro (for profit), deve-se ao menos registrar nestas "considerações finais", mesmo não sendo o escopo do presente texto, que um grande fluxo financeiro em direção aos países centrais é produzido pela mobilidade estudantil internacional (presencial e virtual) ${ }^{23}$, gerando uma espécie transnacionalização, como exportação de educação superior pelas IES sediadas no centro do capitalismo mundial, que estaria travestida de internacionalização. De acordo com dados da OCDE, mais de 4,5 milhões de estudantes, em 2012, estavam matriculados em uma instituição de educação superior fora de seu País de origem, sendo que a maior parte é de

\footnotetext{
22، the current US experience is a version of what I call the "Brazilian Effect": when public higher education cannot keep pace with growing public demand for access and programs, governments often allow FP's to rush in and help fill the gap, becoming a much larger and sometimes dominant provider. This is the pattern in many developing economies such as Brazil where some 50 percent of student enrollment is in profit-driven private institutions and in Korea, Poland and many other parts of the world" (DOUGLASS, 2012, p. 2).

${ }^{23} \mathrm{~A}$ internacionalização solidária da educação superior, por não ser escopo neste artigo, não foi tratada.
} 
origem asiática (53\% do total da mobilidade internacional), principalmente chineses indianos (OCDE, 2014, p. 342) $)^{24}$. Neste sentido, conforme Azevedo,

o que se tem chamado de internacionalização da educação superior é, em grande medida, transnacionalização da educação superior, pois a mobilidade de estudantes tem se fundado, majoritariamente, no comércio de serviços de educação terciária, o que contribui para a formação de um mercado mundial de educação superior e menos para a construção de um campo social global de educação superior (2015, p. 1.161).

O Brasil participa desse fluxo para o exterior com o Programa Ciência sem Fronteiras (CsF) que, vale notar, tem sido justificado como política pública em função da adesão do País ao modelo de desenvolvimento econômico baseado no conhecimento, por isso o CsF tem priorizado a grande área das Ciências Naturais. De acordo com o Decreto n. 7.642, de 13 dez. 2012, de criação do Programa CsF, assume-se que o referido programa contribuirá para o "aumento da competitividade das empresas brasileiras" e que estimulará "as pesquisas aplicadas no País, visando ao desenvolvimento científico e tecnológico e à inovação". Buscando o cumprimento destes objetivos, o Programa CsF prevê alocar mais de $\mathrm{R} \$ 3,2$ bilhões, atribuindo 101.000 bolsas a estudantes e pesquisadores no País e no Exterior, a serem executados em quatro anos - até 2015 (BRASIL, 22 fev 2015).

Entretanto, buscando tirar conclusões no presente artigo, percebe-se que o Brasil é partícipe, de maneira subordinada, do processo de mercadorização da educação superior, com preponderante atuação de grupos transnacionais. Porém, com a ressalva de que, no entanto, há também empresas com sedes no Brasil, organizadas como sociedades anônimas, cujas ações (papéis representativos de valores) são negociadas em bolsa, significando dizer que, na forma da lei, tantos indivíduos como fundos de participação (private equity), associações e fundos previdenciários, nacionais ou estrangeiros, podem estar partilhando por ações a

\footnotetext{
${ }^{24}$ Em trabalho apresentado no Seminário Universitas/BR, Azevedo infere que “(...) que estão se constituindo três grandes espaços ("mercados”) transnacionais de educação superior: 1) Américas/Mundo, nucleado pelos EUA; 2) Europa/Mediterrâneo/África, referenciado no Processo de Bolonha/EEES (Espaço Europeu de Ensino Superior) e focalizado no Reino Unido, França e Alemanha; 3) Oceania/Ásia, multicentrado na Austrália, Nova Zelândia, Japão, China e Coréia do Sul, com preponderância australiana” (2015, p. 1154). Estes espaços geoacadêmicos, segundo Azevedo (2015), destacam-se pelas seguintes características: 1. Anglofonia: a língua inglesa como língua franca, reservatório de conhecimento e veículo de espraiamento da cultura e da ciência; 2 . Reputação: o reconhecimento da qualidade de instituições de educação superior por agências de avaliação e de acreditação (no limite, a aceitação de rankings como proxy de qualidade); 3. Economia baseada no Conhecimento (em inglês, Knowledge Based Economy - KBE): Estes espaços são hegemonizados por países com atratividade acadêmica (estudantes, professores e cientistas) e fundamentam suas estratégias de desenvolvimento em modelos que valorizam o conhecimento, a ciência, a tecnologia e a inovação; e 4. Potência econômico-cultural-militar: em grande medida, as universidades alcançam reconhecimento por reverberar e representar a potência e o poder dos países e regiões em que estão situadas. Pela mesma razão, estas instituições respaldam, na forma de soft power (poder brando), suas sedes (países e regiões). Sobre este último item, vale precisar que, “de acordo com Nye Jr (2011), Smart-power (poder inteligente) é a combinação de soft power (poder brando) e hard-power (poder duro ou coerção). Em especial, soft power é a capacidade de influenciar o comportamento de outros atores ou de conseguir que outros atores tomem como seus interesses que na realidade não o são, por intermédio de meios não violentos e sem a necessidade de efetuar pagamentos. Em outros palavras, é o poder conquistado a partir da capacidade de convencimento, da capacidade industrial avançada e da capacidade de produzir conhecimento de fronteira, inclusive na área militar" (AZEVEDO, 2015, p. 11541155).
}

(c) Rev. Inter. Educ. Sup.[RIESup] Campinas, SP

v.1

n.1

p. $86-102$

jul./set. 2015 
propriedade de uma empresa mercantil fornecedora de ensino, o que, potencialmente, caracteriza (quando há participação acionária estrangeira nas referidas empresas) como uma modalidade de transnacionalização da educação.

Para fins didáticos e futuras problematizações, apresenta-se a seguir um quadro de caracterizações das esferas pública e privada (privado-mercantil). Essas anotações no quadro não estão esgotadas e, certamente, outras características devem ser acrescidas ao que se coloca. Ademais, não é inútil relembrar que o campo da educação superior, em especial, sua esfera pública, está atravessado pelo que Slaughter e Leslie denominaram de "capitalismo acadêmico". Assim como, em grande medida, as IES públicas têm administradas por princípios baseados na Nova Gestão Pública (NGP) ${ }^{25}$. Entretanto, o quadro pode servir de referência do que originalmente seriam ambas as esferas (pública e privada) no campo da educação superior.

Caracterização da esfera administrativa

\begin{tabular}{|c|c|c|}
\hline Interesse & Pública & Privado-Mercantil \\
\hline Motivação & Bem público & Bem privado/particular \\
\hline Administração & Colegiada/compartilhada & Lucro/dividendos \\
\hline Valor acadêmico & Ciência e Conhecimentralizada/particular \\
\hline $\begin{array}{c}\text { Propósito da } \\
\text { atividade }\end{array}$ & Bem comum & Aplicação da aprendizagem \\
\hline Avaliação & Participativa/formativa/processual & Mercado \\
\hline Responsabilidade & Estado & $\begin{array}{c}\text { Resultados/indicadores/boas } \\
\text { práticas }\end{array}$ \\
\hline Tempo & Mediado por conselhos e instâncias & $\begin{array}{c}\text { Acionista/cotista/stockholder/ } \\
\text { proprietário/gestor }\end{array}$ \\
\hline Poder & Reitoria e Conselhos Superiores & Imediato \\
\hline Governo & Autonomia & Heteronomia de mercado \\
\hline Financiamento & Fundo público & Estudantes-clientes/fundos \\
\hline $\begin{array}{c}\text { Vulnerabilidades } \\
\text { Possíveis }\end{array}$ & $\begin{array}{c}\text { Burocratismo/corporativismo/ } \\
\text { mandarinato/estadocentrismo } \\
\text { imobilismo/reunismo/ }\end{array}$ & $\begin{array}{c}\text { Privatismo/autoritarismo/ } \\
\text { insensibilidade/centralização/ } \\
\text { concentração oligopólica } \\
\text { /desvalorização da } \\
\text { ciência/exploração dos } \\
\text { trabalhadores }\end{array}$ \\
\hline Força & Promoção do bem comum & Celeridade \\
\hline
\end{tabular}

Enfim, sendo a educação um bem público, um direito humano e uma ação social que promove a solidariedade cultural entre gerações, a coesão e a integração sociais, sua provisão pelo setor privado-mercantil (em grande medida transnacionalizado), como se a educação fosse uma mercadoria acaba por subverter suas potencialidades de bem público, erodindo,

\footnotetext{
${ }^{25}$ De acordo com Robertson e Verger, a expressão Nova Gestão Pública (NGP) refere-se a um conjunto "de elementos que incluiu metas de desempenho, a transferência do gerenciamento para os gestores, a especifi cação de padrões e indicadores, a alocação regida por resultados, auditoria e terceirização de uma série de atividades que haviam sido uma parte central do setor público" (2012, p. 1.136).
}

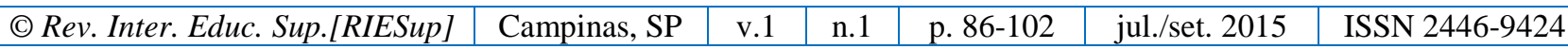


como diria Polanyi (2000), as relações humanas, a solidariedade, a integração, a coesão social a unidade entre as pessoas, e criando oligopólios empresariais e, no limite, o "imperialismo cultural" (Bourdieu; Wacquant, 2002).

\section{REFERÊNCIAS}

ANHEMBI MORUMBI. Rede Internacional Laureate. Extraído de <http://portal.anhembi.br/institucional/rede-internacional-laureate/>, Acesso em 12 Fev 2015.

ANUP. FIES Audiência Pública - Senado Federal Comissão de Direitos Humanos. Apresentação ppt. Brasília:. 2015

AZEVEDO, M.L.N. Internacionalização ou transnacionalização da educação superior: entre a formação de um campo social global e um mercado de ensino mundializado. Anais. XXIII Seminário da rede Universitas/Br. Políticas de Educação Superior no Brasil: a expansão privado-mercantil em questão. Belém/PA, 20 a 23 de maio de 2015, p. 1.138-1.166, ISSN 2446-6123.

AZEVEDO, M.L.N. A economia baseada no "cercamento" do conhecimento: globalização, educação e mercadorias fictícias. In: CHAVES, V.J.; SILVA JR, J.R.; CATANI, A.M. A universidade brasileira e o PNE: instrumentalização e mercantilização educacionais. São Paulo: Xamã, 2013.

BALL, Stephen J. Diretrizes Políticas Globais e Relações Políticas Locais em Educação. Currículo sem Fronteiras, v.1, n.2, pp.99-116, Jul/Dez 2001.

BALL, Stephen J. Performatividade, privatização e o pós-estado do bem-estar. Educação e Sociedade, Campinas, vol. 25, n. 89, p. 1105-1126, Set./Dez. 2004.

BOURDIEU, P.; WACQUANT, L. Sobre as Artimanhas da Razão Imperialista. Estudos Afro-Asiáticos, Ano 24, no 1, 2002, pp. 15-33.

BRASIL. Ciências sem Fronteiras. O Programa. Ministério da Ciência, Tecnologia e Inovação (MCTI). Extraído de http://www.cienciasemfronteiras.gov.br). Acesso em 22 fev 2015.

CARVALHO, C.H.A. O PROUNI no Governo Lula e o jogo político em torno do acesso ao ensino superior. Educação e Sociedade, Campinas, vol. 27, n. 96 - Especial, p. 979-1000, out. 2006.

COMISSÃO EUROPEIA. EUROPA 2020: Estratégia para um crescimento inteligente, sustentável e inclusivo. Comissão Europeia, Bruxelas, 03 Março 2010.

DALE, Roger. Globalização e Educação: demonstrando a existência de uma "Cultura Educacional Mundial Comum" ou localizando uma "Agenda Globalmente Estruturada para a Educação”? Educação e Sociedade, Campinas, vol. 25, n. 87, p. 423-460, maio/ago. 2004. 
DALE, Roger. Estado, Globalização, Justiça Social e Educação: reflexões contemporâneas de Roger Dale. Entrevista a Luís Armando Gandin. Currículo sem Fronteiras, v. 14, n. 2, p. 516, Maio/Ago 2014

DALE, R. ; ROBERTSON, S. Globalisation \& Europeanisation in Education. Oxford: Symposium Books, 2009.

DIAS SOBRINHO, José. Dilemas da Educação Superior no Mundo Globalizado: sociedade do conhecimento ou economia do conhecimento. São Paulo: Casa do Psicólogo, 2005.

DOLOWITZ, D.; MARSH D. Learning from Abroad: The Role of Policy Transfer in Contemporary Policy-Making. Governance: An International Journal of Policy and Administration, Vol. 13, No. 1, January 2000,(pp. 5-24). 2000 Blackwell Publishers, Oxford, UK, ISSN 0952-1895.

DOUGLASS, John Aubrey. Money, politics and the rise of for-profit higher education in the US: a story of supply, demand and the Brazilian effect. Research \& Occasional Paper Series: CSHE.2.12, University of California, Berkeley, 2012.

ENQA. Standards and Guidelines for Quality Assurance in the European Higher Education Area. 3rd. Edition. ENQA: Helsinki, Finland, 2009.

ESTÁCIO. Perfil corporativo. Relação com Investidores. Extraído de <http://www.estacioparticipacoes.com.br/>, acesso em 22 Fev 2015.

FERNANDES, Florestan. Democracia e desenvolvimento: a transformação da periferia e o capitalismo monopolista da era atual. São Paulo: Hucitec, 1972.

HOPER. Análise Setorial do Ensino Superior Privado (Coordenação geral: Ryon Braga). Hoper Group: Foz do Iguaçu, 2009.

HOPER. Cenário mercadológico brasileiro da graduação privada - EaD. Hoper Group: Foz do Iguaçu, 2014.

KROTON. Sobre a Kroton. Extraído de <http://www.kroton.com.br/>, Acesso em 12 Fev 2015.

LEO, Sérgio. Aperfeiçoar as PPPs é vital para a AL, diz Coutinho. Valor Econômico. 25 Jan 2013. Extraído de < http://www.valor.com.br/>, acesso em 20 ago 2015.

LIRA, Davi. Só em 2013, faculdades ganharam R 750 milhões de isenção de impostos com Prouni. iG São Paulo. 28 ago 2014. Extraído de <http://ultimosegundo.ig.com.br/educacao/2014-08-28/so-em-2013-faculdades-ganharam-r750-milhoes-de-isencao-de-impostos-com-prouni.html>, acesso em 22 fev 2015.

LORENZONI, Ionice. PROUNI. Programa completa 10 anos com maior oferta de bolsas desde que foi criado. 26 dez de 2014. Extraído de <portal.mec.gov.br>, Acesso em 22 Fev 2015. 
NYE Jr, Joseph. The Future of Power. New York: Public Affairs (Perseus Books): 2011.

OLIVEIRA, Romualdo P. A transformação da educação em mercadoria no Brasil. Educação e Sociedade, Campinas, vol. 30, n. 108, p. 739-760, out. 2009.

POLANYI, Karl. A grande transformação: as origens de nosso época. tradução de Fanny Wrabel. 2a. ed. Rio de Janeiro: Campus, 2000.

ROBERTSON, Susan; VERGER, Antoni. Educação e Sociedade, Campinas, v. 33, n. 121, p. 1133-1156, out.-dez. 2012.

SÉCCA, Rodrigo Ximenes; LEAL, Rodrigo Mendes. Análise do setor de ensino superior privado no Brasil. BNDES Setorial n. 30, Set. 2009, p. 103-156.

SGUISSARDI, Valdemar. Estudo diagnóstico da política de expansão da (e acesso à) educação superior no Brasil 2002-2012. EDITAL No 051/2014 SESu, PROJETO DE ORGANISMO INTERNACIONAL - OEI, PROJETO OEI/BRA/10/002. CNE: Brasília, 2015.

TOLEDO, José Roberto de. Pátria Especuladora. O Estado de S. Paulo. 16 fev. 2015. Extraído de <http://politica.estadao.com.br/noticias/geral,patria-especuladora-imp,1635087>, Acesso em 22 fev 2015.

TOLEDO, José Roberto de; SALDAÑA, Paulo; BURGARELLI, Rodrigo - O Estado de S. Paulo. Gasto com Fies cresce 13 vezes e chega a R \$13,4 bi, mas ritmo de matrículas cai. $\mathbf{O}$ Estado de S.Paulo. 15 fev. 2015. Extraído de <http://sao-

paulo.estadao.com.br/noticias/geral,gasto-com-fies-cresce-13-vezes-e-chega-a-r-13-4-bi-masritmo-de-matriculas-cai-imp-,1634714>, Acesso em 22 fev 2015.

TOLEDO, José Roberto de; OSCAR, Naiana; SALDAÑA, Paulo; BURGARELLI, Rodrigo. Com novas regras no Fies, mensalidades revertem queda e voltam a subir. O Estado de $\mathbf{S}$.

Paulo. 16 fev. 2015. Extraído de <http://educacao.estadao.com.br/noticias/geral,com-novasregras-no-fies-mensalidades-revertem-queda-e-voltam-a-subir,1634994>, Acesso em 22 fev 2015 .

WIT, Hans de. Internationalization of Higher Education: Nine Misconceptions. International Higher Education. Center for International Higher Education. The Boston College. Boston, $n^{\circ}$. 64, Summer 2011, p. 6-7.

WALLERSTEIN, I. Capitalismo histórico e civilização capitalista. Rio de Janeiro: Contraponto, 2001. 